\title{
The Effect of Postdilatation on Coronary Blood Flow and Inhospital Mortality after Stent Implantation in ST-Segment Elevation Myocardial Infarction Patients
}

\author{
Oktay Şenöz, Ferhat Siyamend Yurdam \\ Department of Cardiology, Bakırcay University Cigli Training and Research Hospital, Izmir, Turkey \\ ORCID: \\ Oktay Şenöz: https://orcid.org/0000-0002-3847-7598 \\ Ferhat Siyamend Yurdam: https://orcid.org/0000-0002-8494-2980
}

\section{Abstract}

Background: Adjunctive balloon postdilatation is often performed after stent deployment to improve stent expansion during percutaneous coronary intervention (PCI). However, aggressive mechanical expansion may increase distal thromboembolization and microvascular injury, especially for patients with ST-segment elevation myocardial infarction (STEMI). Therefore, the benefit of postdilatation in these patients remains controversial. We aimed to investigate the effects of postdilation on coronary blood flow and inhospital mortality. Materials and Methods: A retrospective analysis was made of patients who received primary PCI because of STEMI. A total of 216 patients were included, as 108 applied with postdilatation following stent implantation and 108 not applied with postdilatation using propensity score matching method. Coronary blood flow was evaluated using the thrombolysis in myocardial infarction (TIMI) flow and myocardial blush grade (MBG). Results: The baseline clinical, angiographic, and laboratory characteristics of the groups were similar $(P>0.05)$. No-reflow developed in 34 (15.7\%) of all patients according to TIMI flow (0-2), and in 36 (16.6\%) according to MBG (0-1). While the no-reflow (TIMI $0-2)$ rates of the groups at baseline and following stent implantation were similar $(94.4 \%$ vs. $95.4 \%, P=0.757$ and $23.1 \%$ vs. $20.4 \%$, $P=0.621)$, the final no-reflow (TIMI 0-2) rate was significantly higher in the postdilatation group $(22.2 \%$ vs. $9.3 \%, P=0.009)$. Inhospital mortality rate was determined to be higher in the postdilatation group, but it was statistically nonsignificant $(8.3 \%$ vs. $5.6 \%, P=0.422)$. Conclusion: The application of postdilatation during primary PCI increased the development of no-reflow phenomenon in STEMI patients.

Keywords: Acute myocardial infarction, no-reflow, postdilatation, thrombus burden

\section{INTRODUCTION}

Since the invention and usage of coronary stents, percutaneous coronary intervention (PCI) has become an effective and reliable treatment method that is preferred as the first option in ST-segment elevation myocardial infarction (STEMI) treatment. ${ }^{[1]}$ However, despite the successful opening with a stent of the occluded coronary artery responsible for the infarctus, sufficient myocardial perfusion cannot be obtained in $2.3 \%-29 \%$ of patients. ${ }^{[2,3]}$ This condition, which is known as the no-reflow phenomenon, increases morbidity and mortality. ${ }^{[4,5]}$

\section{Received: 13-08-2021 Revised: 18-10-2021 Accepted: 27-10-2021}

Published Online: 29-01-2022

\begin{tabular}{|l|l|}
\hline \multicolumn{3}{|c|}{ Access this article online } \\
\hline Quick Response Code: & Website: \\
\hline
\end{tabular}

Although the mechanism of the development of no-reflow is not fully known, the most widely accepted theory is the development of microvascular obstruction with plaque or thrombotic material. ${ }^{[6,7]}$ Postdilatation with a noncompliant (NC) balloon following stent placement increases stent expansion and has a positive effect on clinical results. ${ }^{[8-10]}$ Adjunctive balloon postdilatation has been shown to

Address for correspondence: Dr. Oktay Şenöz, Department of Cardiology, Bakırcay University Cigli Training and Research Hospital, Cigli Izmir, Turkey. E-mail: oktayssss@hotmail.com

This is an open access journal, and articles are distributed under the terms of the Creative Commons Attribution-NonCommercial-ShareAlike 4.0 License, which allows others to remix, tweak, and build upon the work non-commercially, as long as appropriate credit is given and the new creations are licensed under the identical terms.

For reprints contact: WKHLRPMedknow_reprints@wolterskluwer.com

How to cite this article: Şenöz O, Yurdam FS. The effect of postdilatation on coronary blood flow and inhospital mortality after stent implantation in ST-segment elevation myocardial infarction patients. Int J Cardiovasc Acad 2021;7:132-9. 
reduce stent thrombosis and revascularization of target vessels in drug-eluting stents (DES) and bare-metal stent (BMS). ${ }^{[1-13]}$ However, the benefit of postdilatation during primary PCI in STEMI patients remains a matter of debate. While some studies have reported that postdilatation after stent placement in STEMI patients is beneficial, ${ }^{[14,15]}$ others have shown that it could be harmful. ${ }^{[16,17]}$

The aim of this study was to investigate the effect of postdilatation following stent implantation on coronary blood flow and inhospital mortality.

\section{Materials and Methods}

\section{Study population}

This study was approved by the ethics committee of Bakırcay University Medicine Faculty (approval number 2021-314). Written informed consent was obtained from each patient included in the study before the procedure.

From a retrospective scan of hospital records, patients were identified who underwent primary PCI because of STEMI between March 2017 and December 2020. A total of 255 patients, 115 applied with postdilatation following stent implantation and 140 not applied with postdilatation, were included in the initial evaluation. Of these, using the propensity score matching method, 216 patients were matched in two groups consisting of 108 patients with similar baseline clinical and angiographic features. Group 1 consisted of patients who underwent postdilatation and Group 2 consisted of patients who did not.

Inclusion criteria were as follows: (1) over 18 years of age, (2) presenting with STEMI, and (3) undergoing primary PCI with successful stent implantation.

Exclusion criteria were as follows: (1) received fibrinolytic treatment, (2) no stent implantation, (3) bifurcation stenting, and (4) presenting with cardiogenic shock.

The demographic, clinical, and angiographic characteristics of the patients included in the study were examined in detail. Medications used before the myocardial infarction and applied during the procedure were recorded.

\section{Laboratory analysis}

The first venous blood samples taken from the patients on presentation at the Emergency Department were examined. A record was made of the results of the renal function tests and liver and cardiac enzyme tests which were performed after 24-48 h for follow-up purposes.

\section{Angiographic and procedural analysis}

All the angiography and PCI procedures were performed with radial or femoral access according to the current guidelines. After admission to the Emergency Department, in addition to the loading of oral $300 \mathrm{mg}$ acetylsalicylic acid, 300-600 mg clopidogrel or $180 \mathrm{mg}$ ticagrelor or $60 \mathrm{mg}$ prasugrel were administered at the discretion of the physician. During the PCI, unfractionated heparin was administered at 5000-10,000 units according to the weight and glomerular filtration rate (GFR) of the patient. Activated clotting time (ACT) was not initially examined routinely in all patients, but in procedures lasting longer than $1 \mathrm{~h}$, ACT was examined, and for those with $<250 \mathrm{sec}$, additional heparin of 2500-5000 units was administered. Bailout glycoprotein (GP) IIb/IIIa inhibitors and manual thrombus aspiration were applied at the physician's discretion to patients with a high thrombus burden. In patients who developed no-reflow phenomenon, intracoronary adenosine, nitroglycerine, and diltiazem were given at appropriate doses for restoration of coronary flow.

Due to the health insurance reimbursement conditions, BMS (Ephesos ${ }^{\mathrm{TM}}$ II, Alvimedica) was used in cases with reference vessel diameter $>3 \mathrm{~mm}$, and for those $\leq 3 \mathrm{~mm}$, DES was used (Everolimus-eluting stents [Xience Pro, Abbott Vascular Devices and Promus Premier, Boston Scientific]). Following stent placement, at the discretion of the physician, postdilatation was performed at 12-18 atmospheres pressure with a NC balloon (NC Quantum Apex, Boston Scientific) of a size appropriate to the reference vessel for stent optimization. Due to the health insurance reimbursement conditions, clear stent imaging was used instead of intravascular ultrasound (IVUS) to evaluate stent expansion. Clear stent imaging is an enhancement of the radiological edge of the stent by digital management of regular X-ray image. The procedure was carried out on a Siemens Artis zee floor-mounted angiography system integrated with CLEARstent software.

The cine-angiograms of all the patients were retrospectively evaluated by the same two experienced cardiologists. The basal thrombolysis in myocardial infarction (TIMI) thrombus score, TIMI flow grade, and myocardial blush grade (MBG) of the infarct-related artery were recorded. Then, the TIMI flow grades and MBG values taken after stent placement, after postdilatation, and finally were evaluated.

\section{Definitions}

STEMI was defined as typical chest pain not relieved by nitroglycerin and ST-segment elevation $1 \mathrm{~mm}$ in at least two limb electrocardiographic leads or $2 \mathrm{~mm}$ in at least two contiguous precordial leads or the presence of new left bundle branch block.

Significant coronary artery disease was defined as the presence of more than $50 \%$ coronary artery stenosis.

Inhospital mortality was defined as mortality from cardiovascular causes after the PCI procedure.

Patients were considered as having heart failure if the left ventricle ejection fraction was lower than $40 \%$ or preserved ejection fraction with echocardiographic, laboratory, and clinical findings suggestive of heart failure. Chronic renal failure was defined as decreased GFR of $<60 \mathrm{ml} / \mathrm{min} / 1.73 \mathrm{~m}^{2}$. Contrast-induced nephropathy was defined as an increase in serum creatinine by either $\geq 0.5 \mathrm{mg} / \mathrm{dl}$ or by $\geq 25 \%$ from baseline within the first $48-72 \mathrm{~h}$ after contrast administration. 
TIMI thrombus score was classified as follows: Grade 0: no thrombus, Grade 1: possible thrombus, Grade 2: the thrombus greatest dimension is $<1 / 2$ vessel diameter, Grade 3: greatest dimension $>1 / 2$ to $<2$ vessel diameters, Grade 4 : greatest dimension $>2$ vessel diameters, and Grade 5: total vessel occlusion due to thrombus. TIMI thrombus score $\geq 4$ was defined high and $<4$ low. ${ }^{[18]}$

TIMI flow grade and MBG were used for the diagnosis of "no-reflow." TIMI flow Grade $<3$ and final MBG $<2$ were described as angiographic no-reflow.

\section{Statistical analysis}

Data obtained in the study were analyzed statistically using SPSS for Windows vn. 25.0 Software (SPSS Inc., Chicago, IL, USA). A propensity score for treatment with postdilatation was estimated for each patient with logistic regression, using 26 clinically and angiographically relevant baseline variables. Thereafter, using 1:1 matching without replacement, a matched cohort was constructed matching each untreated patient to the closest treated patient in which propensity score differed by 0.1 or less. The ability to balance baseline characteristics was assessed by absolute standardized differences (the difference in percentage between the means for the two groups divided by the mutual standard deviation [SD]). Standard differences, $10 \%$, are considered inconsequential. After matching, the overall balance $P$ value was determined as 0.99 .

Conformity of continuous variables to normal distribution was assessed with the Kolmogorov-Smirnov test. Continuous variables were stated as mean $\pm \mathrm{SD}$ values and categorical variables as number $(n)$ and percentage (\%). Comparisons of groups of continuous variables were made using the independent Student's $t$-test or the Mann-Whitney $U$-test according to the normality distribution, and categorical data were compared using the Chi-square test. Coronary blood flow of patients during PCI procedure steps was evaluated with paired-samples $t$-test and repeated measurements analysis of variance test. To determine independent risk factors for no-reflow, first, the clinical parameters were evaluated with univariate regression analysis, and the variables with a value of $P<0.1$ in that analysis were evaluated with multivariate logistic regression analysis. A value of $P<0.05$ was accepted as statistically significant.

\section{Ethical statement}

This study was approved by the local ethics committee of our hospital (Bakırcay University Medicine Faculty [Decision number: 2021-314]).

\section{RESULTS}

Two hundred and sixteen patients with STEMI comprised $166(77 \%)$ males and $50(23 \%)$ females with a mean age of $59.7 \pm 11.8$ years (range, 34-96 years). Of these patients, $76(35.2 \%)$ had hypertension and $74(34.3 \%)$ had diabetes mellitus. The baseline clinical and angiographic characteristics and prestenting procedural data of the patients are presented in
Table 1 . No statistically significant difference was determined between the Group 1 and Group 2 in respect of baseline clinical and angiographic characteristics $(P>0.05)$. In addition, the basal laboratory characteristics were similar in both groups $(P>0.05)$ [Table 2].

Predilatation was applied to $169(78.2 \%)$ patients and direct stent implantation was performed in 47 (21.8\%). GP IIb/IIIa inhibitors were used in 88 (40.7\%) patients and manual thrombus aspiration was applied to $27(12.5 \%)$. The mean stent diameter was $3.1 \pm 0.3 \mathrm{~mm}$ and length was $23.1 \pm 7.8 \mathrm{~mm}$.

While the no-reflow (TIMI 0-2) rates of the groups at baseline and following stent implantation were similar (94.4\% vs. $95.4 \%, P=0.757$ and $23.1 \%$ vs. $20.4 \%, P=0.621$ ), the final no-reflow (TIMI 0-2) rate was significantly higher in the postdilatation group (22.2\% vs. 9.3\%, $P=0.009)$ [Table 3]. Final mean TIMI flow grade and MBG were significantly lower in the postdilatation group $(2.7 \pm 0.6$ vs. $2.87 \pm 0.4$, $P=0.014$, and $2.23 \pm 0.9$ vs. $2.51 \pm 0.7, P=0.008)$. In the postdilatation group, the coronary TIMI flow grade decreased significantly after the balloon postdilatation compared to the before $(P<0.001)$. Coronary blood flow values (TIMI flow grade) and the number of patients who developed normal re-flow during the PCI procedure stages of the groups are presented in Graphs 1 and 2. At the final evaluations, no-reflow was determined to have developed in $34(15.7 \%)$ of all patients according to TIMI flow (0-2) and in $36(16.6 \%)$ according to $\operatorname{MBG}(0,1)$.

Inhospital mortality occurred in $15(6.9 \%)$ patients. Inhospital mortality and postprocedural ventricular arrhythmia rates were determined to be higher in the postdilatation group, but they were statistically nonsignificant $(8.3 \%$ vs. $5.6 \%, P=0.422$, and $7.4 \%$ vs. $3.7 \%, P=0.235$ ) [Table 3 ].

Univariate and multivariate logistic regression analyses were performed to determine no-reflow predictors [Table 4]. The

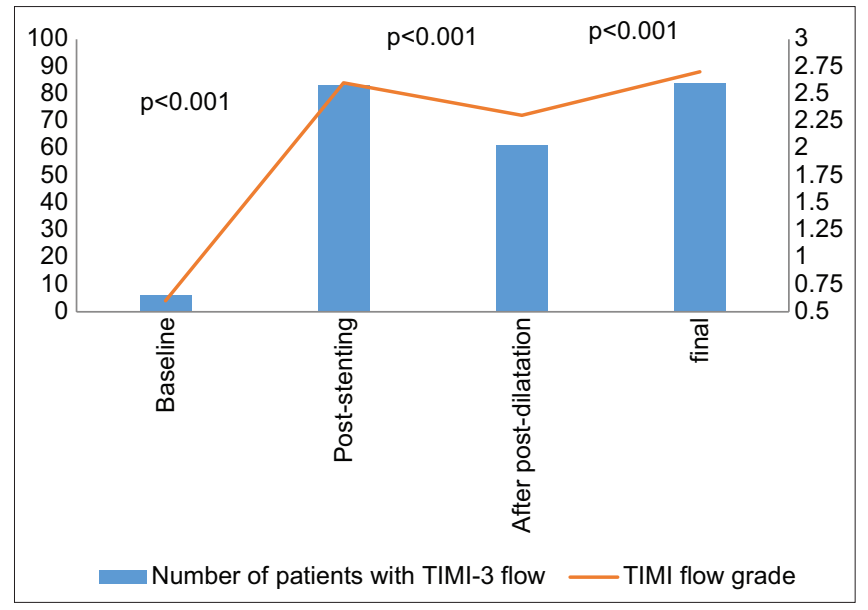

Graph 1: Thrombolysis in myocardial infarction flow grades and the number of patients with normal re-flow during the percutaneous coronary intervention procedure stages of the postdilatation group 


\begin{tabular}{|c|c|c|c|c|}
\hline Variables & Group $1(n=108)$ & Group $2(n=108)$ & Standard differences & $P$ \\
\hline \multicolumn{5}{|l|}{ Baseline clinical features } \\
\hline Male gender, $n(\%)$ & $82(75.9)$ & $84(77.8)$ & 0.018 & 0.747 \\
\hline Age (years), mean \pm SD & $60.2 \pm 12.2$ & $59.2 \pm 11.3$ & 0.085 & 0.515 \\
\hline Diabetes mellitus, $n(\%)$ & $39(36.1)$ & $35(32.4)$ & 0.037 & 0.566 \\
\hline Hypertension, $n(\%)$ & $40(37)$ & $36(33.3)$ & 0.037 & 0.569 \\
\hline Hypercholesterolemia, $n(\%)$ & $46(42.6)$ & $47(43.5)$ & 0.009 & 0.891 \\
\hline Smoking, $n(\%)$ & $57(52.8)$ & $58(53.7)$ & 0.009 & 0.892 \\
\hline Chronic renal failure, $n(\%)$ & $14(13)$ & $12(11.1)$ & 0.018 & 0.676 \\
\hline Cerebrovascular disease, $n(\%)$ & $2(1.9)$ & $2(1.9)$ & 0.000 & 1.000 \\
\hline Prior CAD, $n(\%)$ & $22(20.4)$ & $18(16.7)$ & 0.037 & 0.484 \\
\hline Heart failure history, $n(\%)$ & $5(4.6)$ & $3(2.8)$ & 0.018 & 0.471 \\
\hline Peripheral artery disease, $n(\%)$ & $4(3.7)$ & $7(6.5)$ & 0.027 & 0.353 \\
\hline COPD, $n(\%)$ & $19(17.9)$ & $14(13.3)$ & 0.046 & 0.359 \\
\hline \multicolumn{5}{|l|}{ Previous medication, $n(\%)$} \\
\hline Acetylsalicylic acid & $17(15.7)$ & $14(13)$ & 0.027 & 0.560 \\
\hline Klopidogrel & $4(3.7)$ & $3(2.8)$ & 0.009 & 0.701 \\
\hline Anticoagulant & $3(2.8)$ & $2(1.9)$ & 0.009 & 0.651 \\
\hline ACE-I/ARB & $29(26.9)$ & $25(23.1)$ & 0.037 & 0.530 \\
\hline Beta-blocker & $11(10.2)$ & $9(8.3)$ & 0.018 & 0.639 \\
\hline $\mathrm{CCB}$ & $12(11.1)$ & $9(8.3)$ & 0.027 & 0.491 \\
\hline Spironolactone & $2(1.9)$ & $1(0.9)$ & 0.009 & 0.561 \\
\hline \multicolumn{5}{|l|}{ MI type, $n(\%)$} \\
\hline Anterior MI & $49(45.4)$ & $46(42.6)$ & 0.029 & 0.855 \\
\hline Inferior MI & $51(47.2)$ & $55(50.9)$ & & \\
\hline Other Mis & $8(7.4)$ & $7(6.5)$ & & \\
\hline \multicolumn{5}{|c|}{ ASA plus other antiaggregant loading, $n(\%)$} \\
\hline Klopidogrel & $29(26.9)$ & $28(25.9)$ & 0.009 & 0.877 \\
\hline Ticagrelor or prasugrel & $79(73.1)$ & $80(74.1)$ & & \\
\hline \multicolumn{5}{|l|}{ Baseline angiographic features } \\
\hline \multicolumn{5}{|l|}{ Culprit vessel, $n(\%)$} \\
\hline LAD & $50(46.3)$ & $47(43.5)$ & 0.072 & 0.853 \\
\hline $\mathrm{CX}$ & $20(18.5)$ & $19(17.6)$ & & \\
\hline $\mathrm{RCA}$ & $38(35.2)$ & $42(38.9)$ & & \\
\hline \multicolumn{5}{|l|}{ TIMI thrombus score, $n(\%)$} \\
\hline Low $(0,1,2,3)$ & $47(43.5)$ & $47(43.5)$ & 0.000 & 1.000 \\
\hline High $(4,5)$ & $61(56.5)$ & $61(56.5)$ & & \\
\hline \multicolumn{5}{|l|}{ Baseline TIMI flow grade, $n(\%)$} \\
\hline No reflow $(0,1,2)$ & $102(94.4)$ & $103(95.4)$ & 0.009 & 0.757 \\
\hline Normal reflow (3) & $6(5.6)$ & $5(4.6)$ & & \\
\hline \multicolumn{5}{|l|}{ Baseline MBG, $n(\%)$} \\
\hline No reflow $(0,1)$ & $99(91.7)$ & $99(91.7)$ & 0.000 & 1.000 \\
\hline Normal reflow $(2,3)$ & $9(8.3)$ & $9(8.3)$ & & \\
\hline \multicolumn{5}{|c|}{ Number of vessels with significant CAD, $n(\%)$} \\
\hline One vessel & $52(48.1)$ & $54(50)$ & & 0.954 \\
\hline Two vessels & $37(34.3)$ & $35(32.4)$ & & \\
\hline Three vessels & $19(17.6)$ & $19(17.6)$ & & \\
\hline \multicolumn{5}{|l|}{ Procedural data, $n(\%)$} \\
\hline Balloon predilatation & $87(80.6)$ & $82(75.9)$ & 0.046 & 0.410 \\
\hline Manual thrombus aspiration & $16(14.8)$ & $11(10.2)$ & 0.046 & 0.304 \\
\hline Glycoprotein IIb/IIIa inhibitors using & 45 (41.7) & $43(39.8)$ & 0.018 & 0.782 \\
\hline
\end{tabular}

Group 1: Postdilatation group, Group 2: Nonpostdilatation group, ACE-I: Angiotensin-converting enzyme inhibitors, ARB: Angiotensin II receptor blocker, ASA: Acetylsalicylic acid, CAD: Coronary artery disease, CCB: Calcium channel blockers, COPD: Chronic obstructive pulmonary disease, CX: Circumflex artery; LAD: Left anterior descending artery; MBG: Myocardial blush grade, MI: Myocardial infarction, TIMI: Thrombolysis in MI, RCA: Right coronary artery

independent predictors of no-reflow were determined as $\quad 95 \%$ confidence interval $[\mathrm{CI}]=1.284,6.794 ; P=0.011)$, higher follows: application of postdilatation (odds ratio $[\mathrm{OR}]=2.953 ; \quad$ TIMI thrombus score $(\mathrm{OR}=2.706 ; 95 \% \mathrm{CI}=1.141,6.416$; 
Şenöz and Yurdam: The effect of postdilatation on coronary blood flow in STEMI

\begin{tabular}{|c|c|c|c|}
\hline \multirow[t]{2}{*}{ Variables } & \multicolumn{2}{|c|}{ Mean \pm SD } & \multirow[t]{2}{*}{$P$} \\
\hline & $\begin{array}{l}\text { Group 1 } \\
(n=108)\end{array}$ & $\begin{array}{l}\text { Group } 2 \\
(n=108)\end{array}$ & \\
\hline White blood cell count $\left(\times 10^{9} / \mathrm{L}\right)$ & $12.1 \pm 3.9$ & $12.7 \pm 3.7$ & 0.114 \\
\hline Lymphocyte count $\left(\times 10^{9} / \mathrm{L}\right)$ & $2.4 \pm 1.7$ & $2.6 \pm 1.6$ & 0.242 \\
\hline Neutrophil count $\left(\times 10^{9} / \mathrm{L}\right)$ & $8.7 \pm 3.5$ & $8.9 \pm 4.3$ & 0.795 \\
\hline Monocyte count $\left(\times 10^{9} / \mathrm{L}\right)$ & $0.73 \pm 0.37$ & $0.79 \pm 0.35$ & 0.231 \\
\hline Hemoglobin $(g / D 1)$ & $13.7 \pm 1.9$ & $13.9 \pm 2.1$ & 0.628 \\
\hline Platelet count $\left(\times 10^{9} / \mathrm{L}\right)$ & $263.1 \pm 67.1$ & $248.6 \pm 68.9$ & 0.123 \\
\hline Urea $(\mathrm{mg} / \mathrm{dl})$ & $37.2 \pm 18.9$ & $36.2 \pm 15.1$ & 0.950 \\
\hline Creatinine $(\mathrm{mg} / \mathrm{dl})$ & $1.01 \pm 0.46$ & $1.04 \pm 0.86$ & 0.808 \\
\hline Sodium $(\mathrm{Na})(\mathrm{mmol} / \mathrm{L})$ & $138.4 \pm 2.9$ & $138.4 \pm 4.3$ & 0.985 \\
\hline Potassium $(\mathrm{K})(\mathrm{mmol} / \mathrm{L})$ & $4.2 \pm 0.5$ & $4.3 \pm 0.6$ & 0.175 \\
\hline Fasting blood glucose (mg/dl) & $176.4 \pm 91.8$ & $174.2 \pm 94.9$ & 0.867 \\
\hline Total cholesterol (mg/dl) & $186.9 \pm 48.1$ & $193.1 \pm 42.7$ & 0.406 \\
\hline HDL cholesterol (mg/dl) & $41.8 \pm 13.2$ & $39.9 \pm 11.2$ & 0.261 \\
\hline LDL cholesterol (mg/d) & $115.1 \pm 44.5$ & $118.9 \pm 34.2$ & 0.475 \\
\hline Plasma triglycerides (mg/dl) & $144.3 \pm 75.5$ & $175.4 \pm 145.1$ & 0.376 \\
\hline Hs-cTnT & $604.9 \pm 1516.7$ & $758.7 \pm 1726.1$ & 0.644 \\
\hline
\end{tabular}

$P=0.024)$, and advanced age $(\mathrm{OR}=1.038 ; 95 \% \mathrm{CI}=1.004$, $1.072 ; P=0.028)$.

\section{Discussion}

The short-term effects of postdilatation on STEMI patients were investigated in this study. The results demonstrated that the application of postdilatation following stent implantation increased the development of no-reflow phenomenon in STEMI patients.

Primary PCI with the implantation of a DES is now widely preferred as the first-choice revascularization procedure in patients with STEMI. ${ }^{[19,20]}$ Although angioplasty is developing in terms of materials and techniques, short- and long-term complications, such as stent thrombosis and restenosis, have not yet been completely eliminated. ${ }^{[15,21]}$ To prevent insufficient stent expansion during PCI, the postdilatation procedure is applied with high pressure $\mathrm{NC}$ balloons following stent implantation. The IVUS studies showed that without postdilatation, optimal stent expansion could be achieved in only $15 \%-29 \%$ of patients. ${ }^{[22,23]}$ Postdilatation has been shown to reduce the development of stent thrombosis and in-stent restenosis associated with insufficient stent expansion. ${ }^{[10,11]}$ However, mechanical over-expansion of stents may increase the development of no-reflow and mortality by causing distal embolization. ${ }^{[24]}$

Inflammation, microvascular vasoconstriction, and distal microembolization play a major role in the development of no-reflow. ${ }^{[25,26]}$ As shown in the current study, STEMI patients often have a high thrombus burden in the infarct-related

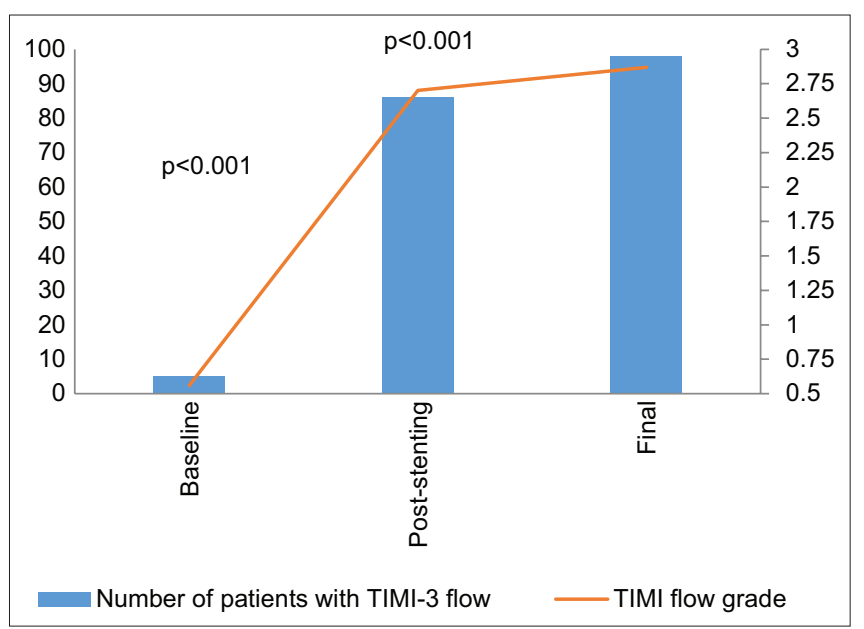

Graph 2: Thrombolysis in myocardial infarction flow grades and the number of patients with normal re-flow during the percutaneous coronary intervention procedure stages of the nonpostdilatation group

artery. The application of postdilatation in these patients can increase the development of no-reflow because of ulcerated and thrombotic plaques. Although several studies have reported that postdilatation during primary $\mathrm{PCI}$ is beneficial and does not cause adverse outcomes, ${ }^{[15,27]}$ most studies have shown that postdilatation during primary PCI increases the development of no-reflow. ${ }^{[16,17,28]}$ In a different study, it was shown that postdilatation increased PCI-related myocardial infarction and mortality approximately twofold in patients with acute myocardial infarction (AMI), but these conditions were not increased in non-AMI patients. ${ }^{[17]}$ Similar to the findings of those studies, the results of the current study showed a statistically significant increase in the development of the no-reflow phenomenon and a numerical increase inhospital mortality with the application of postdilatation. Just like in postdilatation, the frequency of distal microembolization and no-reflow may increase with predilatation. Many previous studies have shown that predilatation during primary PCI increases the development of no-reflow, peri-procedural myocardial infarction, and mortality compared with direct stent implantation. ${ }^{[29,30]}$ However, in the current study, predilation had no effect on no-reflow, as patients with predilatation were distributed similarly to both groups by propensity score matching.

Development of the no-reflow phenomenon during PCI increases the development of congestive heart failure, malignant arrhythmias, and mortality. ${ }^{[3,31]}$ Therefore, eliminating no-reflow and restoration of the coronary flow is important in respect of reducing short- and long-term morbidity and mortality. Pharmacological therapies such as intracoronary sodium nitroprusside, calcium channel blockers, adenosine and GP IIb/IIIa receptor inhibitors, and nonpharmacological therapies such as thrombus aspiration can contribute to the restoration of coronary flow. However, as seen in the current study, final coronary TIMI 3 flow may not be able to be obtained in all patients despite all these treatments. Therefore, 
Table 3: Coronary flow changes during the coronary angioplasty procedure and in-hospital adverse events of the study population

\begin{tabular}{|c|c|c|c|}
\hline Variables & Group $1(n=108), n(\%)$ & Group $2(n=108), n(\%)$ & $P$ \\
\hline \multicolumn{4}{|l|}{ Coronary flow changes } \\
\hline \multicolumn{4}{|l|}{ Baseline TIMI flow grade } \\
\hline No reflow $(0,1,2)$ & $102(94.4)$ & $103(95.4)$ & 0.757 \\
\hline Normal reflow (3) & $6(5.6)$ & $5(4.6)$ & \\
\hline \multicolumn{4}{|l|}{ Baseline MBG } \\
\hline No reflow $(0,1)$ & 99 (91.7) & 99 (91.7) & 1.000 \\
\hline Normal reflow $(2,3)$ & $9(8.3)$ & $9(8.3)$ & \\
\hline \multicolumn{4}{|l|}{ Poststenting TIMI flow grade } \\
\hline No reflow $(0,1,2)$ & $25(23.1)$ & $22(20.4)$ & 0.621 \\
\hline Normal reflow (3) & $83(76.9)$ & $86(79.6)$ & \\
\hline \multicolumn{4}{|l|}{ Poststenting MBG } \\
\hline No reflow $(0,1)$ & $24(22.2)$ & $24(22.2)$ & 1.000 \\
\hline Normal reflow $(2,3)$ & $84(77.8)$ & $84(77.8)$ & \\
\hline \multicolumn{4}{|l|}{ After postdilatation TIMI flow grade } \\
\hline No reflow $(0,1,2)$ & $47(43.5)$ & & \\
\hline Normal reflow (3) & $61(56.5)$ & & \\
\hline \multicolumn{4}{|l|}{ After postdilatation MBG } \\
\hline No reflow $(0,1)$ & $45(41.7)$ & & \\
\hline Normal reflow $(2,3)$ & $63(58.3)$ & & \\
\hline \multicolumn{4}{|l|}{ Final TIMI flow grade } \\
\hline No reflow $(0,1,2)$ & $24(22.2)$ & $10(9.3)$ & 0.009 \\
\hline Normal reflow (3) & $84(77.8)$ & $98(90.7)$ & \\
\hline \multicolumn{4}{|l|}{ Final MBG } \\
\hline No reflow $(0,1)$ & $26(24.1)$ & $10(9.3)$ & 0.003 \\
\hline Normal reflow $(2,3)$ & $82(75.9)$ & $98(90.7)$ & \\
\hline \multicolumn{4}{|l|}{ Inhospital adverse events } \\
\hline Inhospital mortality & $9(8.3)$ & $6(5.6)$ & 0.422 \\
\hline Postprocedural ventricular arrhythmia & $8(7.4)$ & $4(3.7)$ & 0.235 \\
\hline Contrast-induced nephropathy & $4(3.7)$ & $5(4.6)$ & 0.733 \\
\hline
\end{tabular}

Group 1: Postdilatation group, Group 2: Nonpostdilatation group, $n$ : Number of patients, MBG: Myocardial blush grade, MI: Myocardial infarction, TIMI:

Thrombolysis in myocardial infarction

Table 4: Evaluation of the factors that may affect the development of coronary no-reflow by logistic regression analysis

\begin{tabular}{|c|c|c|c|c|}
\hline \multirow[t]{2}{*}{ Variables } & \multicolumn{2}{|c|}{ Univariate logistic regression } & \multicolumn{2}{|c|}{ Multivariate logistic regression } \\
\hline & OR (95\% CI) & $P$ & OR (95\% CI) & $P$ \\
\hline Gender (female) & $1.479(0.654-3.348)$ & 0.348 & & \\
\hline Age & $1.040(1.007-1.073)$ & 0.016 & $1.038(1.004-1.072)$ & 0.028 \\
\hline Diabetes mellitus & $1.228(0.576-2.618)$ & 0.595 & & \\
\hline Hypertension & $1.006(0.467-2.164)$ & 0.988 & & \\
\hline Smoking & $1.308(0.623-2.748)$ & 0.478 & & \\
\hline Hypercholesterolemia & $1.395(0.669-2.906)$ & 0.374 & & \\
\hline Prior CAD & $2.111(0.916-4.867)$ & 0.08 & $1.427(0.536-3.801)$ & 0.477 \\
\hline MI type (inferior MI) & $0.875(0.476-1.607)$ & 0.667 & & \\
\hline Culprit vessel (RCA) & $0.723(0.474-1.103)$ & 0.132 & & \\
\hline Number of diseased vessels & $0.982(0.356-2.708)$ & 0.971 & & \\
\hline HF history & $5.933(1.407-25.015)$ & 0.015 & $3.134(0.614-16.010)$ & 0.170 \\
\hline CVD history & $1.808(0.182-17.916)$ & 0.613 & & \\
\hline Chronic renal failure & $1.736(0.641-4.702)$ & 0.278 & & \\
\hline TIMI thrombus score (high) & $2.434(1.077-5.503)$ & 0.033 & $2.706(1.141-6.416)$ & 0.024 \\
\hline Predilatation & $1.357(0.526-3.501)$ & 0.528 & & \\
\hline Postdilatation & $2.800(1.267-6.189)$ & 0.011 & $2.953(1.284-6.794)$ & 0.011 \\
\hline
\end{tabular}

CI: Confidence interval, OR: Odds ratio, CAD: Coronary artery disease, CVD: Cerebrovascular diseases, HF: Heart failure, RCA: Right coronary artery, MI: Myocardial infarction, TIMI: Thrombolysis in MI 
the correct approach is to identify and avoid the potential causes of no-reflow before it occurs. The current study analysis determined a high TIMI thrombus score and advanced age as well as the application of postdilatation to be independent predictors of no-reflow. Prospective studies conducted on elderly patients with AMI demonstrate that inhospital and long-term mortality rates are higher and the success rate of primary PCI is lower than for younger patients. ${ }^{[32,33]}$ Some predisposing factors for no-reflow, such as diffuse coronary atherosclerosis, severe vascular calcification, and disrupted microcirculation, are common in elderly patients. These pathological changes probably cause a tendency to distal embolization during primary PCI, consequently resulting in the no-reflow phenomenon. ${ }^{[34]}$ STEMI patients have a high thrombus burden and this increases the risk of distal thromboembolization through spontaneous or mechanical fragmentation. ${ }^{[6,35]}$ In several previous studies, it has been determined that a high thrombus burden increases distal embolization and no-reflow and could be an independent predictor for the development of no-reflow. ${ }^{[36-38]}$ Spontaneous distal microembolization may occur in the presence of high thrombus burden, but this risk increases exponentially, especially when postdilatation is applied. Therefore, postdilatation should be avoided in this patient group.

\section{Study limitations}

This was a retrospective and nonrandomized study. Therefore, the diagnosis of no-reflow was made from retrospective angiographic findings, and the gold standard methods of magnetic resonance perfusion imaging and myocardial contrast echocardiography could not be performed. Due to insurance reimbursement conditions, postdilatation was performed under the guidance of CLEARstent instead of IVUS, which is the gold standard for evaluating optimal stent deployment. This can be seen as a limitation, but in recent years, some studies have stated that CLEARstent applications can be used in daily practice for stent placement guidance ${ }^{[3,40]} \mathrm{A}$ further limitation of the study was that long-term results of postdilatation could not be evaluated.

\section{Conclusion}

This study demonstrated that the application of postdilatation during primary PCI increased the development of no-reflow phenomenon in STEMI patients. It can be predicted that no-reflow may develop in patients with postdilatation, high thrombus burden, and advanced age.

\section{Financial support and sponsorship}

Nil.

\section{Conflicts of interest}

There are no conflicts of interest.

\section{References}

1. Task Force on the management of STseamiotESoC; Steg G, James SK, Atar D, Badano LP, Blömstrom-Lundqvist C, et al. ESC Guidelines for the management of acute myocardial infarction in patients presenting with ST-segment elevation. Eur Heart J 2012;33:2569-619.

2. Harrison RW, Aggarwal A, Ou FS, Klein LW, Rumsfeld JS, Roe MT, et al. Incidence and outcomes of no-reflow phenomenon during percutaneous coronary intervention among patients with acute myocardial infarction. Am J Cardiol 2013;111:178-84.

3. Yildiz A, Yuksel M, Oylumlu M, Polat N, Akyuz A, Acet H, et al. The utility of the platelet-lymphocyte ratio for predicting no reflow in patients with ST-segment elevation myocardial infarction. Clin Appl Thromb Hemost 2015;21:223-8.

4. Bolognese L, Carrabba N, Parodi G, Santoro GM, Buonamici P, Cerisano G, et al. Impact of microvascular dysfunction on left ventricular remodeling and long-term clinical outcome after primary coronary angioplasty for acute myocardial infarction. Circulation 2004;109:1121-6.

5. Akpek M, Kaya MG, Lam YY, Sahin O, Elcik D, Celik T, et al. Relation of neutrophil/lymphocyte ratio to coronary flow to in-hospital major adverse cardiac events in patients with ST-elevated myocardial infarction undergoing primary coronary intervention. Am J Cardiol 2012;110:621-7.

6. Topol EJ, Yadav JS. Recognition of the importance of embolization in atherosclerotic vascular disease. Circulation 2000;101:570-80.

7. Kotani J, Nanto S, Mintz GS, Kitakaze M, Ohara T, Morozumi T, et al. Plaque gruel of atheromatous coronary lesion may contribute to the no-reflow phenomenon in patients with acute coronary syndrome. Circulation 2002;106:1672-7.

8. Johansson B, Allared M, Borgencrantz B, Brorson L, Geijer HK, Kellerth L, et al. Standardized angiographically guided overdilatation of stents using high pressure technique optimize results without increasing risks. J Invasive Cardiol 2002;5:221-6.

9. Brodie BR, Cooper C, Jones M, Fitzgerald P, Cummins F; Postdilatation Clinical Compartative Study (POSTIT) Investigators. Is adjunctive balloon postdilatation necessary after coronary stent deployment? Final results from the POSTIT trial. Catheter Cardiovasc Interv 2003;59:184-92.

10. Yoon HJ, Hur SH. Optimization of stent deployment by intravascular ultrasound-review. Korean J İntern Med 2012;27:30-8.

11. Brodie BR. Adjunctive balloon postdilatation after stent deployment: İs it still necessary with drug-eluting stents? J Interv Cardiol 2006;19:43-50.

12. Moussa I, Moses J, Di Mario C, Albiero R, Gregorio JD, Adamian M, et al. Does the specific intravascular ultrasound criteria used to optimize stent expansion have an impact on the probability of stent restenosis? Am J Cardiol 1999;83:1012-7.

13. Russo RJ, Attubato MJ, Davidson CJ, DeFranco AC, Fitzgerald PJ, Iaffaldano RA, et al. Angiography versus intravascular ultrasounddirected stent placement: Final results from AVID. Circulation. 1999;100:I-234.

14. Karjalainen PP, Niemelä M, Laine M, Airaksinen JK, Ylitalo A, Nammas W. Usefulness of post-coronary dilation to prevent recurrent myocardial infarction in patients treated with percutaneous coronary intervention for acute coronary syndrome (from the BASE ACS trial). Am J Cardiol 2017;119:345-50.

15. Tasal A, Bacaksız A, Vatankulu MA, Turfan M, Erdogan E, Sonmez O, et al. Is postdilatation with a noncompliant balloon necessary after coronary stent deployment during primary angioplasty? J Interven Cardiol 2013;26:325-31.

16. Soylu K, Ataş AE, Yenerçağ M, Akçay M, Şeker O, Aksan G, et al. Effect of routine postdilatation on final coronary blood flow in primary percutaneous coronary intervention patients without angiographic stent expansion problems. J Investig Med 2018;66:1096-101.

17. Zhang ZJ, Marroquin OC, Stone RA, Weissfeld JL, Mulukutla SR, Selzer F, et al. Differential effects of post-dilation after stent deployment in patients presenting with and without acute myocardial infarction. Am Heart J 2010;160:979-86.e1.

18. Duman H, Çetin M, Durakoğlugil ME, Değirmenci H, Hamur H, Bostan M, et al. Relation of angiographic thrombus burden with severity of coronary artery disease in patients with ST segment elevation myocardial infarction. Med Sci Monit 2015;21:3540-6.

19. Andersen HR, Nielsen TT, Rasmussen K, Thuesen L, Kelbaek H, Thayssen $\mathrm{P}$, et al. DANAMI-2 Investigators. A comparison of coronary 
angioplasty with fibrinolytic therapy in acute myocardial infarction. N Engl J Med 2003;349:733-42.

20. Keeley EC, Boura JA, Grines CL. Primary angioplasty versus intra-venous thrombolytic therapy for acute myocardial infarction: A quantitative review of 23 randomised trials. Lancet 2003;361:13-20.

21. Sabate M, Cequier A, Iñiguez A, Serra A, Hernandez-Antolin, Mainar V, et al. Everolimus-eluting stent versus bare-metal stent in ST-segment elevation myocardial infarction (EXAMINATION): 1 year results of a randomised controlled trial. Lancet 2012;380:1482-90.

22. Cheneau E, Satler LF, Escolar E, Suddath WO, Kent KM, Weissman NJ, et al. Underexpansion of sirolimus-eluting stents: İncidence and relationship to delivery pressure. Catheter Cardiovasc Interv 2005;65:222-6.

23. Aziz S, Morris JL, Perry RA, Stables RH. Postdilatation following coronary stent deployment: Lesion and procedural characteristics associated with an increase in stent dimensions. J Invasive Cardiol 2008;20:342-6.

24. Gibson CM, Kirtane AJ, Boundy K, Ly H, Karmpaliotis D, Murphy SA, et al. Association of a negative residual stenosis following rescue/ adjunctive percutaneous coronary intervention with impaired myocardial perfusion and adverse outcomes among ST-segment elevation myocardial infarction patients. J Am Coll Cardiol 2005;45:357-62.

25. Eeckhout E, Kern MJ. The coronary no-reflow phenomenon: A review of mechanisms and therapies. Eur Heart J 2001;22:729-39.

26. Şenöz O, Emren SV, Erseçgin A, Yapan Emren Z, Gül İ. Platelet-Lymphocyte ratio is a predictor for the development of no-reflow phenomenon in patients with ST-segment elevation myocardial infarction after thrombus aspiration. J Clin Lab Anal 2021;35:e23795.

27. Biswas S, Soon KH, Lim YL. Angiographic and clinical outcomes of stent postdilatation in ST-Elevation myocardial infarction. Heart Lung Circ 2012;21:684-8

28. Maekawa Y, Asakura Y, Anzai T, Ishikawa S, Okabe T, Yoshikawa T, et al. Relation of stent overexpansion to the angiographic noreflow phenomenon in intravascular ultrasound-guided stent implantation for acute myocardial infarction. Heart Vessels 2005;1:13-8.

29. Loubeyre C, Morice MC, Lefèvre T, Piéchaud JF, Louvard Y, Dumas P. A randomized comparison of direct stenting with conventional stent implantation in selected patients with acute myocardial infarction. J Am Coll Cardiol 2002;39:15-21.

30. Piscione F, Piccolo R, Cassese S, Galasso G, D'Andrea C, De Rosa R, et al. Is direct stenting superior to stenting with predilation in patients treated with percutaneous coronary intervention? Results from a meta-analysis of 24 randomised controlled trials. Heart 2010;96:588-94.

31. Morishima I, Sone T, Okumura K, Tsuboi H, Kondo J, Mukawa H, et al. Angiographic no-reflow phenomenon as a predictor of adverse long-term outcome in patients treated with percutaneous transluminal coronary angioplasty for first acute myocardial infarction. J Am Coll Cardiol 2000;36:1202-9.

32. Singh M, Mathew V, Garratt KN, Berger PB, Grill DE, Bell MR, et al. Effect of age on the outcome of angioplasty for acute myocardial infarction among patients treated at the Mayo Clinic. Am J Med 2000;108:187-92.

33. Barakat K, Wilkinson P, Deaner A, Fluck D, Ranjadayalan K, Timmis A. How should age affect management of acute myocardial infarction? A prospective cohort study. Lancet 1999;353:955-9.

34. Kirma C, Izgi A, Dundar C, Tanalp AC, Oduncu V, Aung SM, et al. Clinical and procedural predictors of no-reflow phenomenon after primary percutaneous coronary interventions: Experience at a single center. Circ J 2008;72:716-21.

35. Svilaas T, Vlaar PJ, Van der Horst IC, Diercks GF, De Smet BJ, Heuvel VD, et al. Thrombus aspiration during primary percutaneous coronary intervention. N Engl J Med 2008;358:557-67.

36. Tanboga IH, Topcu S, Aksakal E, Kalkan K, Sevimli S, Acikel M. Determinants of angiographic thrombus burden in patients with ST-segment elevation myocardial infarction. Clin Appl Thromb Hemost 2014;20:716-22

37. Ke D, Zhong W, Fan L, Chen L. Delayed versus immediate stenting for the treatment of ST-elevation acute myocardial infarction with a high thrombus burden. Coron Artery Dis 2012;23:497-506.

38. Silber S, Albertsson P, Avilés FF, Camici PG, Colombo A, Hamm C, et al. Guidelines for percutaneous coronary interventions. The task force for percutaneous coronary interventions of the European Society of Cardiology. Eur Heart J 2005;26:804-47.

39. Tanaka N, Pijls NH, Koolen JJ, Botman KJ, Michels HR, Brueren BR, et al. Assessment of optimum stent deployment by stent boost imaging: Comparison with intravascular ultrasound. Heart Vessels 2013;28:1-6.

40. Davies AG, Conway D, Reid S, Cowen AR, Sivananthan M. Assessment of coronary stent deployment using computer enhanced x-ray images-validation against intravascular ultrasound and best practice recommendations. Catheter Cardiovasc Interv 2013;81:419-27. 